\title{
ARTIGOS
}

\section{ESTÉTICA DA SUSTENTABILIDADE: O VALOR AMBIENTAL PERCEBIDO POR MEIO DOS ASPECTOS VISUAIS DO PRODUTO}

\section{AESTHETICS OF SUSTAINABILITY: THE ENVIRONMENTAL VALUE PERCEIVED THROUGH THE VISUAL ASPECTS OF THE PRODUCT}

THAMYRES OLIVEIRA CLEMENTINO, M.SC. | UFPE

AMILTON J. V. DE ARRUDA, PhD. | UFPE

ITAMAR FERREIRA DA SILVA, Dr. | UFCG

\begin{abstract}
RESUMO
O presente artigo expõe uma discussão sobre a estética da sustentabilidade aplicada em produtos industriais como forma de comunicar aos consumidores o valor ambiental agregado. Aborda a percepção do público como recurso para investigar quais e como os aspectos visuais estéticos podem ser adotados para caracterizar produtos ecologicamente corretos, por meio da estética empírica. Nesta perspectiva, apresenta uma breve revisão de literatura, contextualizando a estética do objeto e a atual conjuntura do debate sobre a estética da sustentabilidade em produtos industriais. Por fim, apresenta o resultado de uma revisão sistemática que objetivou levantar trabalhos com foco nos aspectos visuais estéticos associados ao valor ambiental agregado, com a finalidade de expor dados comprovados e aplicáveis no âmbito projetual.
\end{abstract}

PALAVRAS CHAVE: Design de produto; sustentabilidade; estética.

\begin{abstract}
This article presents a discussion on the aesthetics of sustainability applied to industrial products as a way of communicating to consumers the added environmental value. It addresses the public's perception as a resource to investigate which and how the visual aesthetic aspects can be adopted to characterize ecologically correct products, through empirical aesthetics. In this perspective, it presents a brief literature review, contextualizing the aesthetics of the object and the current situation of the debate on the aesthetics of sustainability in industrial products. Finally, it presents the result of a systematic review that aimed to survey works with a focus on aesthetic visual aspects associated with the added environmental value, in order to expose proven and applicable data in the project scope.
\end{abstract}

KEY WORDS: Product design; sustainability; aesthetic 


\section{INTRODUÇÃO}

Produtos que adotam soluções ambientalmente mais sustentáveis vêm surgindo como uma alternativa aos convencionais - mais danosos, empregando, para isto, estratégias como a minimização de recursos (matéria prima, energia, transporte, entre outros); a escolha de processos de baixo impacto ambiental (seleção de materiais e processos atóxicos); a otimização da vida dos produtos (durabilidade dos produtos, reaproveitamento de componentes e reciclagem); a extensão de vida dos materiais; e a facilidade de desmontagem e reparo (flexibilidade, adaptabilidade, desmontagem autorizada) (MANZINI e VEZZOLI, 2016; VEZZOLI, 2010; KAZAZIAN, 2005).

Pode-se afirmar que o emprego destas diretrizes projetuais, pautadas na sustentabilidade ambiental, fomentaram o surgimento de uma nova categoria de produtos que se afastam das práticas insustentáveis convencionais e se comprometem com a questão ambiental. Os "ecologically oriented products" utilizam estratégias visando a diferenciação baseada em atributos ecológicos, fornecendo benefícios ambientais maiores ou impondo custos ambientais menores do que os demais (ORSATO, 2006; ORSATO, 2002, p.14). Segundo Manzini e Vezzoli (2016), estes produtos buscam atender as necessidades de bem-estar social, utilizando uma quantidade drasticamente inferior de recursos ambientais aos níveis atualmente praticados.

Este assunto conduz a uma questão importante discutida neste artigo, a comunicação entre estes produtos ecologicamente orientados e os consumidores. $\mathrm{O}$ Instituto AKATU (2018) trata deste tema ao indicar a falta de informação como uma questão-chave, que representa barreiras para o consumidor brasileiro. De acordo com a pesquisa realizada pelo instituto "nota-se que o consumidor quer e precisa saber mais sobre tais produtos, para derrubar barreiras e para acionar gatilhos". Neste cenário descrito, a distinção entre os produtos convencionais e aqueles que adotam práticas menos danosas ao meio ambiente se torna relevante, já que, de acordo com Vezzoli (2010, p.49), "uma inovação ambientalmente sustentável, sem ser percebida como uma melhoria (comparada com as soluções obsoletas), não é suficiente", isto porque segundo o autor, inviabiliza que consumidores as diferenciem das demais soluções - insustentáveis, o que por sua vez impede o posicionamento favorável ao consumo mais consciente, que pode surgir a partir do valor agregado a estes produtos.

Segundo Cardoso (2013), valor agregado consiste no valor a mais que um bom projeto pode acrescentar ao produto em comparação aos concorrentes, que de acordo com Kruken e Trusen (2009), pode ser indicado por meio da qualidade percebida, que é o conjunto de dimensões de valor inerentes ao produto, sendo elas: valor funcional ou utilitário; valor emocional; valor social; valor econômico; e valor ambiental. Este artigo ocupa-se do 'valor ambiental' agregado ao produto, que segundo estes autores, consiste na percepção dos consumidores sobre a "prestação de serviços ambientais por meio do uso sustentável dos recursos naturais". Segundo eles, o valor ambiental deve ser trabalhado de maneira estratégica, objetivando facilitar a percepção do consumidor sobre os produtos envolvidos com práticas menos danosas, contribuindo, assim, para a conscientização sobre os valores envolvidos na produção e no consumo.

Mas, como enfatizar para o consumidor o valor ambiental em produtos ecologicamente orientados? Como caminho possível, tem-se a "visualidade", que permite expressar os valores invisíveis do produto através de aspectos visuais estéticos perceptíveis aos olhos dos consumidores. Para Cardoso (2013) por meio da visualidade, o designer pode sugerir atitudes, estimular comportamentos e equacionar problemas complexos. Para compreender a visualidade, parte-se da definição deste autor sobre a forma (IBID, 2013), considerando três aspectos interligados: 1) Aparência: aspecto perceptível pelo olhar; 2) Configuração: arranjo das partes; e 3) Estrutura: dimensão constitutiva.

Nesta perspectiva, é possível adentrar na área da "estética do objeto", em que, afirma Löbach (2001), são descritas as características visuais dos objetos e suas qualidades, por meio de investigações empíricas que permitam avaliar ideias e valores estéticos em grupos determinados de pessoas, por meio de suas preferências. É possível encontrar na literatura algumas pesquisas que se ocupam desta questão, objetivando investigar os efeitos dos aspectos visuais estéticos para a comunicação do valor ambiental agregado em produtos. $O$ objetivo deste artigo é discutir esta questão, bem como apresentar um breve levantamento sobre as indicações já presentes na literatura.

\section{ESTÉTICA DO OBJETO}

A estética pode ser considerada a ciência da percepção sensorial e dos conhecimentos adquiridos através dela. Estético é tudo aquilo que se percebe sensorialmente através dos sentidos.

O sensorial pertence à relação entre a materialidade daquilo que é percebido e os sentidos do sujeito (BOMFIM, 2001).

Esta perspectiva corrobora para a compreensão dos objetos por meio da percepção visual, favorecendo o entendimento do processo de comunicação entre seres 
humanos e o entorno. Bürdek (2006) afirma que o design é uma disciplina que produz não apenas realidades materiais, mas também comunicação. O autor aborda o tema ao expor a teoria de Theodor Elligner (1966), em que é apresentado o conceito de "informação do produto", considerando que há uma linguagem do produto constituída por aspectos como dimensão, forma, superfície, material, configuração, entre outros fatores que podem influenciar positiva ou negativamente o potencial comprador. Segundo o autor o conceito de "linguagem do produto", confirmou que o design deve se encarregar principalmente das relações homem-objeto, ou seja, das ligações entre usuário e objeto, em especial nas funções perceptivas, por meio das quais se intermediam os sentimentos das pessoas (IBID, 2006, p.293).

Löbach (2001) aborda que as funções exercidas pelo produto criam um relacionamento com o usuário a partir do uso, que por sua vez, torna possível o estabelecimento de impressões positivas ou não. É importante lembrar que cada produto convive com diferentes funções, que devem ser pensadas a fim de suprir as necessidades do usuário e do projeto, sendo elas a função prática, estética e simbólica (Figura 01).

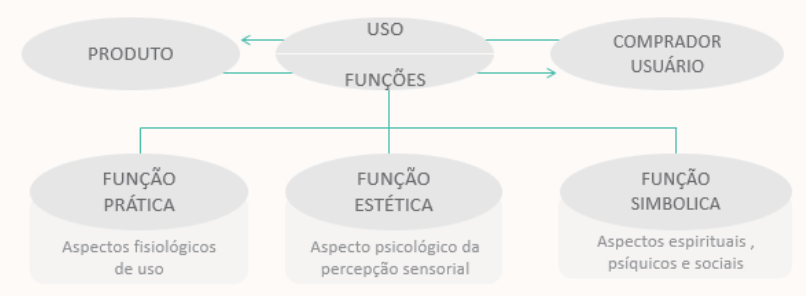

Figura 01 - Embalagem confeccionada em material com aparência sustentável Fonte: LÖBACH (2001).

Segundo Löbach (2001) a função estética está vinculada à configuração da aparência do produto, que para Cardoso (2013), corresponde ao aspecto perceptível pelo olhar. Bürdek (2006) afirma que a função formal-estética está relacionada à vivência de impressões sensoriais de elementos formais, em que, afirma Löbach (2001), ocorre à relação entre o produto e o usuário no nível dos processos sensórios.

Para Silveira (2018) deve-se salientar que a função estética de um produto não se resume, ao fator sensorial, pois quando se experimenta o funcionamento estético, também se adentra no crivo do juízo, a partir do discernimento do usuário, o que indica que a função estética é de natureza sensório-cognitiva/sensório-comunicativa. Esta afirmação vai ao encontro do que afirma Löbach (2001), ao indicar que a função estética e a função simbólica têm estreita relação e interdependência, isto porque a função simbólica visa estabelecer ligações entre os produtos e as experiências e sensações vividas anteriormente pelo usuário, criando associações. Para isto depende dos aspectos visuais estéticos empregados no produto, como forma, cor, superfície, entre outros, que permitam a associação de ideias.

Para Cardoso (2013) as características visuais e morfológicas dos produtos sugerem significados e relações, permitindo que se crie uma especificidade discursiva própria. Deste modo, pode-se afirmar que "a função simbólica é, antes de tudo, uma função estética, que ultrapassa a realidade imediata proporcionada pela aparência do artefato, e adquire natureza simbólica" (SILVEIRA, 2018, p. 80).

Para criar a função estética de um produto é preciso levar em consideração as condições perceptivas de indivíduos, que seja capaz de dotar os produtos com características alinhadas à percepção sensorial do usuário. Ao projetar a função estética, a partir de aspectos visuais estéticos, o designer contribuirá para que o indivíduo reconheça o ambiente artificial que o cerca, atendendo às condições de percepção (LÖBACH, 2001). Para compreender o uso sensorial dos produtos, dois fatores são essenciais (IBID, 2001): (1) Experiências anteriores com as características estéticas, aqui entendidas como os aspectos visuais estéticos (forma, cor etc.); e (2) Percepção consciente dessas características. Nesta perspectiva é possível citar Bense (2009), que considera as relações de natureza estética como um processo de comunicação, correspondendo a duas vias de um processo único, como observa-se a seguir no esquema proposto pelo autor (Figura 02):

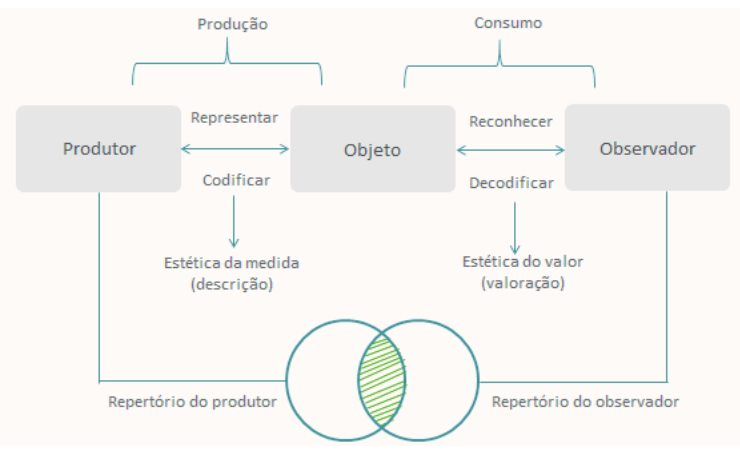

Figura 02 - Diagrama da comunicação estética Fonte: baseado em Bense (2009, P.142).

Nele, representa-se o processo de comunicação estética a partir de dois polos que culminam no objeto que significa (aqui entendido como a embalagem) e gera efeitos de ordem estética. O primeiro polo consiste no produtor, ocorrendo a comunicação criativa, que corrobora para os processos gerativos e de manipulação, estando ainda, a 
responsabilidade de julgamento e seleção, organização da forma, tornando-a tangível e sujeita a apreciação. Já o outro polo corresponde a comunicação ajuizadora, em que o observador aprecia a forma, julgando-a e avaliando-a sob critérios de valor.

Segundo Silveira (2018) “Essas fases distintas se sobrepõem o tempo todo, e fazem parte de um fenômeno maior que é, na integralidade, a comunicação estética. $O$ modelo preserva diferenças de natureza, comunicacional-estética entre os interagentes, produtor e observador". Semelhante ao diagrama de comunicação proposto por Bense, Löbach (2001), propôs uma versão baseada na teoria da informação e focada na área do design (Figura 03):

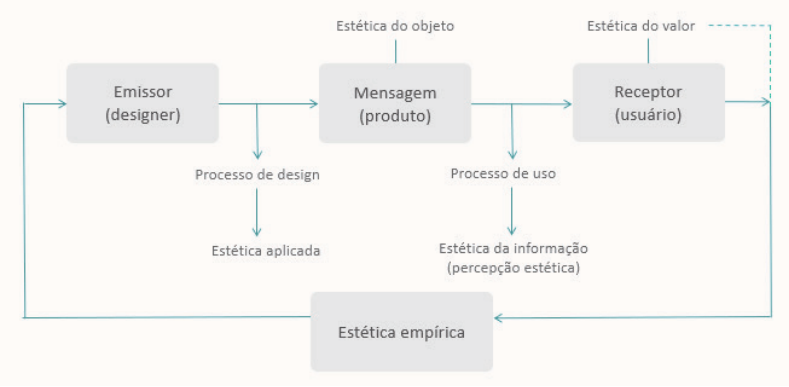

Figura 03 - A comunicação estética do design industrial. Fonte: baseado em Löbach (2001)

Nela, o autor coloca o designer como o emissor de mensagens em forma de produtos e o usuário como receptor das mensagens estéticas inerentes aos produtos, criando a relação entre designer, produto e usuário. Segundo Silveira (2018) "no processo da comunicação estética há uma série de outros processos e inter-relações, entre as quais ganham relevo o processo que acontece da relação entre designer e produtos e o que ocorre no domínio estabelecido entre produto e usuário". No processo existente entre o designer e o produto (Emissor/mensagem) ocorre a produção estética ou processo de design, englobando a estética aplicada, que se encarrega de questões relativas à configuração dos produtos. Já no processo que envolve produto e usuário (mensagem/receptor), define-se o que Löbach (2001) descreve como a estética da informação, a estética do valor e a estética empírica, que direciona os estudos para a busca pela compreensão entre o usuário e à percepção estética do produto. Para Silveira (2018), é neste ponto que se fecha o círculo da comunicação estética, já que nele se apresenta de forma sistemática a cadeia de fenômenos estéticos suscitados pelos produtos criados pelos seres humanos e suas relações com o designer e o usuário. Segundo a autora "tais inter-relações entre essas várias ocorrências possibilitam, de modo abrangente, a percepção e compreensão do processo de comunicação estética no âmbito do design".

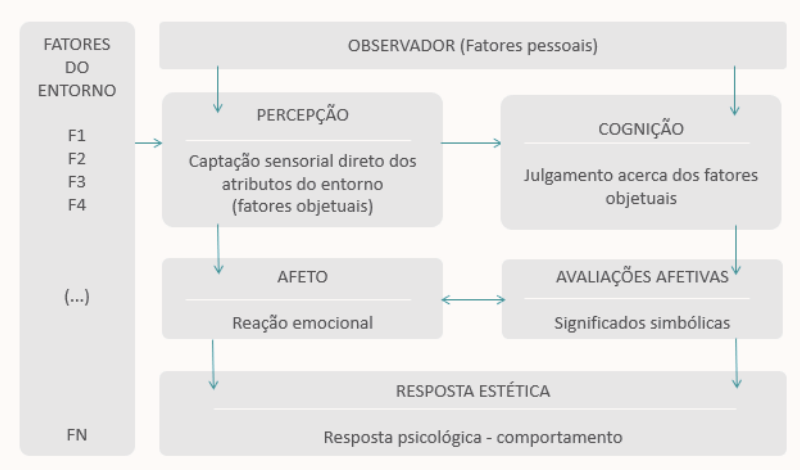

Figura 04 - Diagrama da comunicação estética Fonte: baseado em Nasar (2000)

A escolha correta de aspectos visuais estéticos pode contribuir para a percepção adequada acerca do valor ambiental agregado em produtos, podendo uma configuração obter respostas melhores que outras a partir da percepção do público, que está atrelada a experiências anteriores. Deste modo, é possível conjecturar que a comunicação de produtos com valor ambiental deva ser pautada na percepção do consumidor, permitindo a facilitação do contato entre o produto ecologicamente orientado, e o consumidor consciente, mediante estratégias ligadas a estética empírica, que gere dados para análise das melhores alternativas compositivas.

Mas, para que isso ocorra, é necessário que todos os aspectos visuais estéticos dos produtos sejam conhecidos e enumerados, tornando-se possível projetar um produto industrial novo, que atenda aos valores fixados no processo de design pelo designer industrial e que corresponda às necessidades estético-perceptivas do usuário. (LÖBACH, 2001, p.158). Walker (2005) afirma que para construir uma tipologia estética, certos identificadores estéticos podem ser propostos, de modo a serem comuns a muitos bens de consumo, e desta forma vir a ser "coletivamente" úteis na distinção de práticas insustentáveis.

Na discussão mantida neste artigo, é proposto que os indicadores estéticos para comunicação do valor ambiental agregado partam da configuração estético simbólico-funcional do produto, o que é compreendido a partir dos aspectos visuais estéticos, tal qual abordados por Löbach (2001), ao dividi-los, para melhor compreensão, em:

- Figura: consiste na soma dos elementos configuradores e das relações estabelecidas por eles; 
- Elementos: responsáveis por constituir uma figura, sendo também portadores da informação estética do produto. Entre os elementos mais relevantes, segundo o autor, são a forma, o material, a superfície e a cor, mas outros são admitidos; e

- Constituição da figura: consiste no tipo de elementos configurativos, seu conjunto, distribuição quantitativa e relação com o todo.

Para o autor (IBID, 2001, p.159-160), a configuração estético simbólico-funcional é determinada pelo conjunto de seus elementos configuradores, que podem influenciar a sensibilidade e ideias dos usuários. Os elementos configurativos podem ser descritos como portadores da informação estética de um produto, e sua seleção e combinação, pelo designer industrial, definirá a reação que o futuro usuário apresentará frente ao produto, podendo o uso correto destes interferir positivamente na comunicação acerca do valor agregado em produtos.

\subsection{Estética Empírica}

Qualquer "coisa" que provoque uma reação em algum órgão do sentido é considerada como um estímulo, sendo passível de gerar resposta por parte de um observador a partir da percepção, que é considerada como um processo baseado na ação, na probabilidade e na experiência (FARINA et al, 2011). Para Löbach (2001), a percepção estética do entorno material apresenta-se mediante dois processos parciais:

A primeira fase consiste na visão, que capta a imagem, e a segunda fase é a percepção, que tem como objetivo tornar consciente a imagem que foi captada. Assim, é possível afirmar que a "percepção é um processo pelo qual uma aparência estética se transforma em significado" (LÖBACH, 2011, p. 171), ou seja, os aspectos visuais estéticos presentes no produto tornam-se responsáveis por gerar nos indivíduos estímulos que culminarão no julgamento acerca dos fenômenos visuais. Isto é exposto por Nasar (2000) ao abordar as respostas avaliativas do entorno. Para o autor, os estímulos do entorno moldam nossos sentimentos, pensamentos e comportamento a partir do processo a seguir:

Em que, observa-se inicialmente o indivíduo sendo exposto aos fatores do entorno, compreendidos aqui como os aspectos visuais estéticos adotados para a configuração dos produtos, como formas, cores, superfícies, entre outros atributos que juntos são percebidos sensorialmente pelos observadores, munidos de fatores pessoais provenientes de suas experiências anteriores e propósitos. Essa combinação, entre fatores do entorno e fatores pessoais, resulta na percepção estética, que consiste na captação sensorial direta do entorno através da visão (1 a fase, objetiva), influenciando os pensamentos dos indivíduos, que buscam estruturar, reconhecer e apreender as informações captadas (cognição - 2a fase subjetiva). A partir disto é possível transformar "produtos" em significado, pois a percepção das características do entorno evoca sentimentos viscerais, que combinados aos pensamentos (avaliações emocionais), produzem pensamentos reflexivos (avaliações cognitivas), que podem afetar o comportamento humano (NASAR, 2000).

Isto foi endossado por Cardoso (2013), ao afirmar que toda vez que um indivíduo olha para um produto associa-o a uma série de valores e juízos ligados à história individual e coletiva, o que faz com que os artefatos materiais possuam sua própria linguagem, que podem ser traduzidas para registro por meio de características visuais e morfológicas. Trata-se de um processo subjetivo, influenciado pela imagem atual da percepção, pela memória de cada pessoa, experiências anteriores, conceitos de valor e normas socioculturais.

Ainda segundo o autor, é possível que os conceitos presentes no imaginário da população encontrem expressão material, pois as formas são expressivas de um processo de significação, que consiste na troca entre aquilo que está embutido em sua materialidade e aquilo que pode ser compreendido/percebido deles por nossas experiências. Sendo assim, qualquer objeto é mediado por sistemas simbólicos.

O significado reside, assim, na percepção dos usuários, sendo a comunidade determinante para o que o produto quer dizer, a partir da experiência, que é um dos fatores mais determinantes do significado. Os designers podem fazer uso estratégico da memória para refinar seus projetos, sendo muitos os modos de criar correspondência entre design, memória e identidade. O repertório existente pode ser utilizado para introduzir ruídos e criar dissonâncias, tanto quanto para reforçar significados aparentes, sendo possível afirmar que as coisas materiais falam de si em termos próprios a sua configuração. (CARDOSO, 2013). Neste contexto, torna-se razoável pensar que, a escolha correta de aspectos visuais estéticos pode contribuir para a percepção adequada acerca do valor ambiental agregado aos produtos, podendo uma configuração obter respostas melhores que outras, a partir do que foi estabelecido mediante aplicação da estética empírica.

Para Löbach (2001), a estética do objeto é parte do processo estético por meio do qual os aspectos perceptivos são avaliados em relação a percepção dos usuários. Nela se descrevem as características visuais do objeto e suas qualidades, que podem ser investigadas por meio da estética 
empírica, responsável por pesquisar ideias sobre valores estéticos em grupos determinados de pessoas, por meio de suas preferências, que no caso desta pesquisa, consiste na escolha de estratégias configuracionais estético simbólico-funcional que melhor comuniquem o valor ambiental agregado. Os dados apresentados por este modelo fornecem base para o desenvolvimento de diretrizes projetuais aplicáveis pelo designer, o que torna este profissional emissor de mensagens em forma de produtos industriais.

Seguindo o pensamento da estética empírica, o usuário se torna peça fundamental para a configuração de produtos, sendo as informações referentes as suas preferências, determinantes no projeto. Isso ocorre pois, de acordo com o autor, os usuários desenvolvem seus próprios conceitos estéticos, elaborados por meio de suas vivências e experiências do passado e o designer pode se valer deles mediante métodos que permitam sua averiguação (estética empírica).

Mas, para que isso ocorra, é necessário que todos os aspectos visuais estéticos dos produtos sejam conhecidos e enumerados, tornando-se possível projetar um produto industrial novo, que atenda aos valores fixados no processo de design pelo designer industrial e que corresponda às necessidades estético-perceptivas do usuário (LÖBACH, 2001, p.158).

\section{ESTÉTICA DA SUSTENTABILIDADE}

Neste artigo a abordagem estética adotada é a que se ocupa da aparência, conectando a percepção dos indivíduos aos produtos. Mas, torna-se importante ressaltar, ao discutir a estética da sustentabilidade ${ }^{1}$ especificamente, que o termo está atrelado, geralmente, a duas linhas de discussão mais consistentes, que de certo modo estão relacionadas, sendo a primeira referente a ética ${ }^{2}$ (MANZINI, 2006; (CASTRO, 2008) e a segunda promovendo o debate sobre a aparência dos produtos com valor ambiental agregado. Este tópico se debruça na linha de pesquisa referente a aparência de produtos com valor ambiental, trazendo autores que contribuíram com a discussão, sobretudo aqueles que expõem o papel do design para a diferenciação estética destes produtos.

Para Zafarmand et al. (2003) o estudo da estética é um fator fundamental para a sustentabilidade, pois consiste em uma das características tangíveis do processo de Desenvolvimento Sustentável, capaz de gerar efeitos nos usuários, incluindo a atração, satisfação, comportamento, atitude e cultura. Para eles, a estética do produto pode atrair clientes antes e durante a compra; afetar emocionalmente o comportamento e a interação do usuário com o produto; influenciar a imaginação, os gostos e as atitudes dos usuários em relação ao produto e sua marca, o ambiente e os valores de mercado; e pode gradualmente transmitir a sensação de um novo estilo de vida, valores socioculturais reais e toda a filosofia da sustentabilidade. Isto demonstra a importância de pesquisas que objetivem descrever estratégias neste campo, diferenciando os produtos ecologicamente orientados dos demais, favorecendo assim o reconhecimento do valor ambiental agregado. Neste viés, é possível promover discussões sobre (IBID, 2003):

1) A importância da estética para a sustentabilidade em geral:

Nesta perspectiva, Manzini (2008) afirma que as habilidades do design devem dar coerência aos produtos e serviços, criando soluções sustentáveis, mas além disto, devem comunicar visões e sistemas de forma adequada, para que o reconhecimento e avaliação de produtos ecologicamente mais coerentes sejam favorecidos. Vezzoli (2010, p.49) acrescenta que a estética tem papel fundamental na efetivação de soluções sustentáveis, já que um produto ecologicamente orientado sem ser percebido como melhoria, comparada a soluções obsoletas, "não é suficiente".

2) A estética especial de produtos sustentáveis,

Defendido por Walker (2005) em seu trabalho "Desmascarando o objeto: reestruturando o design para a sustentabilidade". Nele o autor afirma que os objetos sustentáveis "serão" marcadamente diferentes dos produtos existentes, bem como "terão" tipologia estética bastante diferenciada. Alinhado a este pensamento o autor propôs identificadores estéticos que, coletivamente, fossem uteis na distinção de práticas danosas proveniente dos produtos, capazes de caracterizar tipos de bens de consumo "insustentáveis", sendo eles (IBID, p.49): (a) ser culturalmente neutro ou moderado; (b) livre de impurezas, polido e frágil; (c) oculto e disfarçado; (d) frio ou distante; (e) curvo, arredondado e suave; (f) da moda ou atraente; e (g) completo e inviolável.

Neste viés, Walker (2005) propôs que a estética de produtos com valor ambiental se distanciasse de tais abordagens, trazendo para ilustrar tal situação o "Design de grupo", em que novos produtos são projetados mediante união de partes obsoletas. Nele, diferentes objetos descartados são colocados lado a lado, a fim de recontextualizá-los para criação de um novo produto funcional. A intenção do autor estava em indicar possibilidades estéticas para a diferenciação entre produtos com valor ambiental agregado e os demais, insustentáveis.

Esta medida pode ser compreendida a partir do que foi exposto por Zafarmand et al. (2003), ao indicar que alguns aspectos inerentes ao valor ambiental agregado à 
produtos provocam mudanças em sua estética. Para eles, se um produto é projetado para ser sustentável, ou seja, durável, atualizável, reparável, renovável, modular, reparável, reutilizável e/ou reciclável, a sua estética não envolve as particularidades estéticas atribuídas anteriormente a produtos não sustentáveis. Seria o exemplo da embalagem biodegradável abaixo, produzida com fibra de coco, sendo uma alternativa as embalagens de polímero, e atingindo, com o material, uma aparência de produto com valor ambiental e do e dos óculos confeccionados a partir de canudos reciclados, que mostra uma estética diferenciada.

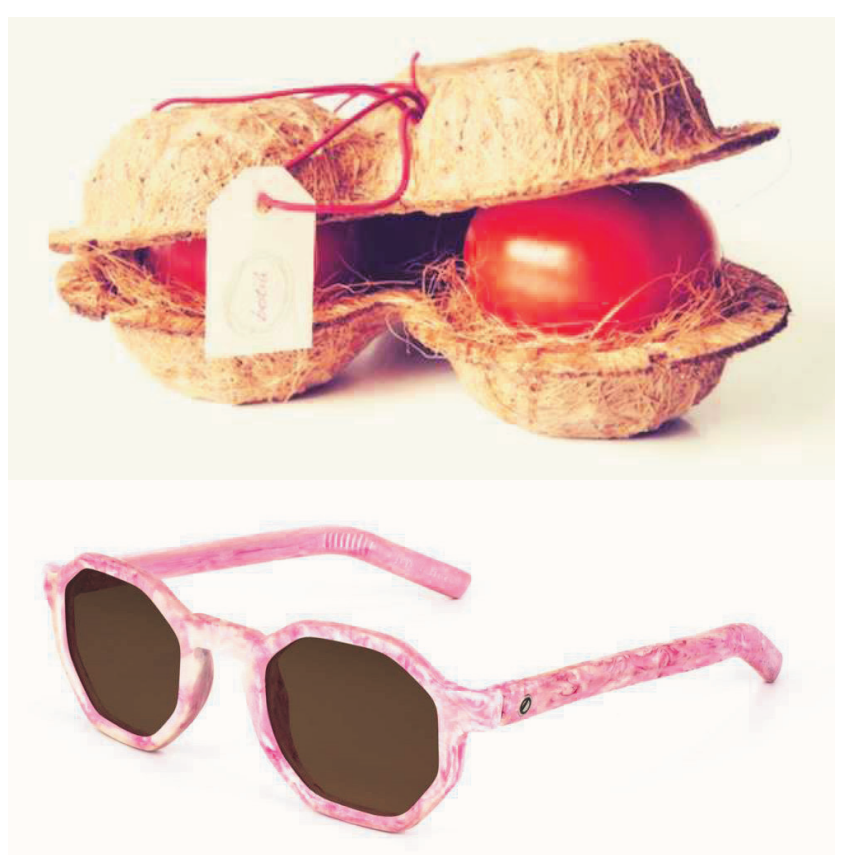

Figura 05 - embalagem de fibra e óculos confeccionado com canudos descartados Fonte: Google imagens

Debruçada neste ponto, Clementino e Arruda (2018) investigaram a estética sustentável com foco no desenvolvimento de embalagens ecologicamente orientadas, objetivando compreender se os requisitos projetuais sustentáveis atualmente praticados poderia apresentavam potencial para interferir na aparência deste produto. A partir de uma revisão de literatura, elencaram os principais elementos configurativos dos produtos industriais, relacionando-os aos requisitos inerentes ao projeto de embalagens com valor ambiental agregado. Os dados, demonstraram que os requisitos ambientais adotados no projeto podem interferir na aparência do produto.

Os requisitos estudados se mostraram aptos a intervir no modo como se comportam os elementos presentes na estética das embalagens - forma, superfície, material, cor, entre outros, o que por sua vez permitiu o desenvolvimento de indicativos estéticos que dialogassem com uma ampla quantidade de embalagens sustentáveis produzidas na atualidade. Os esboços iniciais, apresentados no artigo desenvolvido, sugerem os seguintes marcadores estéticos evidentes nas embalagens com valor ambiental (IBID2018):

\begin{tabular}{|l|}
\hline $\begin{array}{l}\text { Indicadores estéticos para projeto de embalagens } \\
\text { ecologicamente orientadas }\end{array}$ \\
\hline Tamanho reduzido; \\
\hline Integração entre as partes - unidade; \\
\hline Sem partes/adereços/componentes excedentes; \\
\hline Partes conectadas com mesmo material ou encaixe; \\
\hline $\begin{array}{l}\text { Preferencialmente adoção de um mate- } \\
\text { rial, ou menor quantidade possível; }\end{array}$ \\
\hline Resistência aparente; \\
\hline Adaptabilidade; \\
\hline Material reciclado ou passível de reciclagem; \\
\hline $\begin{array}{l}\text { Superfícies sem ranhuras/protuberâncias que dificultem limpeza } \\
\text { para reciclagem; }\end{array}$ \\
\hline Redução na quantidade de cor adotada. \\
\hline Redução nos níveis de saturação na cor; \\
\hline Redução na quantidade de imagens utilizadas; \\
\hline Imagens simbólicas/icônicas; \\
\hline informaçães em locais apropriados/visíveis; \\
\hline Redução da quantidade de fontes adotadas; \\
\hline Redução no emprego de cor tipográfica; \\
\hline Adoção de poucos recursos de acabamento nas superfícies. \\
\hline Apelo afetivo; \\
\hline Limpeza visual; \\
\hline Pequeno número de elementos configurativos; \\
\hline
\end{tabular}

Quadro 01 - Indicadores estéticos

Fonte: Clementino e Arruda, 2018.

Isto ocorre, segundo Zafarmand et. al (2003), pois idealmente, no caso de mudanças na tecnologia, produção e sistema socioeconômico, a estética do produto mudaria acentuadamente. Portanto, um sistema socioeconômico sustentável ao lado de uma tecnologia sustentável, produção e mercado lançaria produtos excepcionais, revelando sua estética especial (IBID, 2003). Alinhado a este pensamento, Walker (2005) "conceitua" produtos ecologicamente orientados como aqueles que consigam romper completamente com os processos de fabricação/tecnologias disponíveis na atualidade, o que por sua vez proporcionaria um novo modelo estético, com resultados diferentes dos presenciados nos produtos convencionais atuais.

Porém, ao analisar alguns produtos com valor ambiental agregado, considerados na atualidade, percebe-se, na verdade, grande semelhança com os produtos 
convencionais, diferente do que foi apresentado pelos autores. Como a exemplo da garrafa de polímero produzida pela Coca-Cola, em que é substituído o petróleo por cana-de-açúcar ou a coleção de canetas BIC, confeccionadas com material de descarte (Figura 06 e 07). Observa-se que a aparência dos produtos mantém a estética dos convencionais, insustentáveis, sendo apenas diferenciadas pelos símbolos/informação que remetem ao seu valor ambiental.

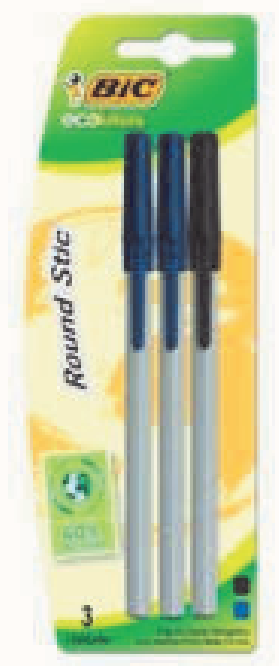

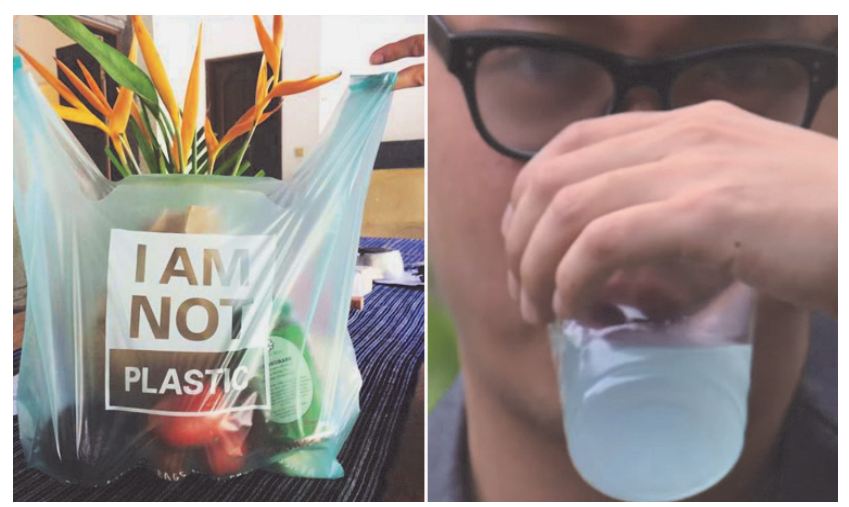

Figura 08 - Embalagem solúvel em água produzida em Bali, na indonésia Fonte: Google imagens

Esta semelhança, ocorre provavelmente, pois os produtos com valor ambiental agregado são derivados de processos de fabricação e técnicas, que embora sigam diretrizes projetuais diferentes, ainda consistem predominantemente, em produtos produzidos industrialmente, com o mesmo tipo de concepção dos produtos convencionais. Este fator torna-se difícil de alterar, já que segundo Vezzoli (2010, p.29), a reorientação para soluções sustentáveis pode trazer muito mais resultados efetivos do que, provavelmente, retomar os velhos modelos de produção e consumo, como os propostos por Walker (2005, p.62), com a rejeição de fatores de design tais como perfeição estética e estilização. $\mathrm{O}$ que se busca na verdade, é que a indústria siga modelos similares aos presentes na natureza, como na ecologia industrial, em que a organização se aproxima do funcionamento do sistema natural, combinando os tecnociclos e os biociclos entre si, mas, não que seja extinta como processo produtivo (MANZINI e VEZZOLI, 2016, p.54).

Assim, pode-se afirmar que muitos dos produtos ecologicamente orientados no contexto atual continuarão sendo produzidos de forma similar aos produtos convencionais, sendo o seu resultado estético, provavelmente, predominantemente similar a estes produtos. Nem sempre as soluções munidas de valor ambiental terão aparência diferente dos produtos convencionais. Então, qual seria o caminho para levar estes produtos a serem percebidos como ecologicamente orientados? A resposta pode ser encontrada no próximo ponto proposto por Zafarmand et al. (2003).

3) critérios estéticos relacionados à sustentabilidade do produto.

Este último ponto foi contemplado neste artigo, com o objetivo de discutir o design como responsável por encontrar caminhos para melhorar a comunicação do valor ambiental agregado, nem sempre evidenciado nos produtos ecologicamente orientados. Walter (2005) argumenta, neste sentido, que "uma tipologia estética não 
está baseada na função do produto, mas, sim, em pontos tácteis e visíveis de forma e acabamento", que poderiam conectar os aspectos visuais estéticos dos produtos aos seus modos de produção, que podem ser sustentáveis ou não. Para o autor "uma tipologia estética seria um meio de estabelecer o problema em termos de design", revelando o que não deveríamos fazer, a partir da estética.

Neste sentido, Pantaleão (2016), expõe o resultado formal-estético como reflexo da manifestação do pensamento do design, capaz de refletir na experiência estética, que por sua vez, abrange espaços além da contemplação formal (física, material). O autor discorre que um design voltado a sustentabilidade deve ser acompanhado de uma postura diferenciada por parte do designer, sendo este fator um agente de modificação na qualidade dos produtos. Ele argumenta que para que haja uma "função estética sustentável" - termo cunhado por Walter, é necessário equilibrar a função estética e prática, mediante intermediação da função simbólica. Neste sentido, ele indica que haja por parte do designer (autor) a subversão na lógica do planejamento, geralmente com foco no objeto, para a promoção de uma psicologia do consumo, capaz de prover o bem-estar pessoal, sociocultural e ambiental. O autor segue afirmando que o design (obra), deve priorizar identificadores estéticos que fortaleçam a relação entre usuário e produto. Além disto, também expõe o usuário (integrante), como atuante no desenvolvimento do produto.

Nesta perspectiva, é possível perceber a relevância em repensar os produtos ecologicamente orientados, integrando a função prática e estética à função simbólica, a fim de estabelecer produtos com valor ambiental agregado como diferenciados dos demais. Neste viés, conjectura-se que o designer deve trabalhar a função prática atrelada a valores estéticos que comuniquem o valor ambiental através da função simbólica, que parte da compreensão acerca do repertório da população sobre o tema, traduzindo tais informações para aspectos visuais estéticos do produto.

De acordo com Luchs e Kumar (2014), para que esse sinal seja eficaz, o produto deve ser intencionalmente projetado para se diferenciar visualmente dos produtos comuns. Embora projetar um produto para parecer visualmente distinto possa parecer arriscado, a pesquisa realizada por eles sugere que as empresas realmente têm alguma margem para buscar uma estratégia de design estético diferenciado. Mesmo que o produto seja considerado esteticamente inferior aos produtos concorrentes, os autores sugerem que esse é um trade-off que não impede a preferência de consumidores que valorizam especialmente a sustentabilidade.
Fica evidente que para alcançar resultados eficazes para a estética de produtos com valor ambiental, a resposta reside no âmbito da comunicação estética, que ocorre entre designer, produto e consumidor. O designer, por meio de sua competência ligada a configuração dos produtos, favorece a busca por soluções capazes de materializar o conceito de valor ambiental, já arraigado no imaginário da sociedade; e a sociedade, que vem amadurecendo seu entendimento sobre o conceito de sustentabilidade ambiental, e por sua vez pode, por meio de seu repertório, apresentar caminhos para a construção de indicadores estéticos capazes de diferenciar os produtos ecologicamente orientados (Figura 09).

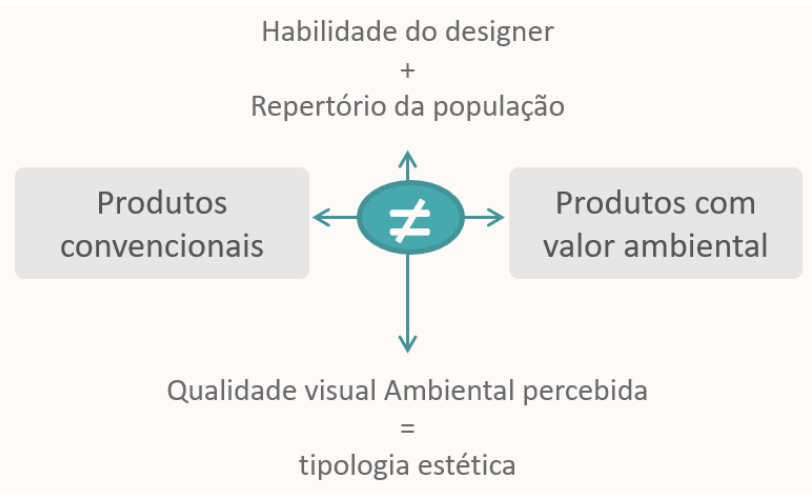

Figura 09 - Esquema proposto pela autora para construção de indicadores estéticos focados no valor ambiental

Fonte: Autora

Para Cardoso (2012, p.250), o embate entre o 'consumir mais, para gerar riquezas' e o 'consumir menos, para preservar recursos' ainda é uma das questões mais difíceis no campo do design no século XXI, sendo uma tarefa para toda a sociedade, já que no mundo complexo os problemas demandam soluções coletivas e não se concentram apenas em um único campo de conhecimento. Nesta pesquisa esta questão é direcionada ao designer juntamente com o consumidor, que segundo Löbach (2001, p.187), desenvolve seus próprios conceitos, elaborados por meio de suas vivências e experiências do passado. Caminho razoável, visto a necessidade, segundo Vezzoli (2001), de se buscar um pluralismo estético para a estética da sustentabilidade.

Walker (2005), já apresentava a necessidade de construir uma tipologia estética divergente entre produtos sustentáveis e convencionais, sendo necessário para isto traçar indicadores estéticos que possam se tornar comuns a muitos bens de consumo, podendo ser coletivamente úteis na distinção de práticas insustentáveis. Vezzoli (2010) afirma que a estética deve se originar nos valores sustentáveis 
presentes na população, podendo assumir várias formas, dependendo do contexto e do designer. Mas, onde buscar estes valores para o estabelecimento de uma estética própria aos produtos ecologicamente orientados?

O tópico a seguir apresenta pesquisas que expõem a percepção do público como parte da construção estética dos produtos, bem como trabalhos que já demonstram resultados na busca por indicadores estéticos que favoreçam o desenvolvimento de produtos com valor ambiental, contribuindo para que o designer consiga trazer diferenciação ao produto, mesmo quando este não contar com produção que propicie uma aparência sustentável. Nesta perspectiva Bonsiepe (2011) afirma que a ciência do design deve fornecer subsídios para melhorar a prática, favorecendo a criação de disciplinas projetuais que capacitem os alunos para reflexão e os auxiliem, sobretudo, nas áreas de comunicação e design industrial. $\mathrm{O}$ autor ilustra esta necessidade afirmando que se um design recebe hoje a incumbência de projetar uma embalagem sustentável não poderá evitar a busca por conhecimentos científicos que o dê embasamento para a atividade projetual.

\subsection{Trabalhos Afins: aspectos visuais estéticos e percepção do valor ambiental agregado}

A percepção acerca dos aspectos visuais estéticos aparece em pesquisas de diversas áreas do design, objetivando trazer compreensão acerca dos melhores meios para proporcionar comunicação entre os produtos e os consumidores. Tendo como finalidade a integração das decisões do projeto à percepção do público.

Adentrando no tema deste artigo, na busca pela comunicação do valor ambiental agregado Zafarmand et al. (2003), realizaram uma revisão de literatura objetivando elencar estudos que abordassem os atributos estéticos práticos para a sustentabilidade do produto. Para isto, selecionaram 160 palavras-chave sobre estética do produto, provenientes de 50 referências sobre design de produto sustentável, publicados de 1984 a 2002. Na pesquisa, foram discriminadas sete categorias principais: "durabilidade estética"; 'Atualização estética e modularidade'; "Simplicidade e minimalismo"; 'Lógica e funcionalidade'; 'Formas e materiais naturais'; 'Identidade estética e cultural local'; e "individualidade e diversidade". De acordo com os autores, para melhorar as tendências e os valores estéticos do mercado e fortalecer o valor ambiental, esses atributos poderiam fornecer aos designers instruções para novos projetos e negócios, além de permitirem a aplicação como diretrizes para o gerenciamento e desenvolvimento da estética de produtos com valor ambiental.
Santos (2012) em sua dissertação Avaliação da percepção dos usuários sobre a comunicação da sustentabilidade em produtos: o modelo persus, investigou a comunicação de produtos ecologicamente orientados, centrando o projeto na forma como o usuário percebia as estratégias de sustentabilidade. $\mathrm{O}$ objetivo estava em apresentar um modelo experimental de métodos da percepção aplicados ao design de produtos, buscando informações relevantes sobre o processo de comunicação de estratégias e recursos do design para a sustentabilidade, por meio do discurso dos usuários acerca dos produtos apresentados. $O$ contato com informações sobre características técnicas foi visto como um fator capaz de alterar a percepção dos usuários sobre produtos, sendo a informação reforçada pelos indivíduos participantes aos associarem o valor ambiental, predominantemente ao tipo de material (Monomaterial ou biodegradável) e através de tamanho e peso do produto.

Salek e Formiga (2015) em artigo intitulado Greenwash my hair: um estudo de caso acerca das percepções de sustentabilidade em embalagens de xampu e condicionador sob a ótica do consumidor, investigaram as percepções do consumidor na relação entre sustentabilidade e embalagens de condicionador e xampu. Eles concluem que a cor da embalagem é o primeiro aspecto observado, sendo o uso do verde um forte indicador de sustentabilidade. Também apontam para o uso de transparência, clareza e limpeza visual como artificio para atrair a percepção acerca da sustentabilidade em xampus e condicionadores, além de palavras e imagens relacionadas à sustentabilidade como "eco", "verde" e "sustentável".

No artigo intitulado Avaliação da percepção dos consumidores sobre a dimensão ecológica das embalagens alimentícias: uma análise visual a autora Clementino et al. (2017), avaliou graficamente as embalagens com valor ambiental a partir da percepção do público. Os dados apontaram para a importância da percepção do público na construção de estéticas que facilitem a comunicação da orientação da embalagem, sendo eles: a forma de trabalhar a composição visual da embalagem, com alta pregnância; e a forma de empregar os elementos constitutivos, reduzindo a paleta de cor e a saturação, adotando o uso do verde em detalhes, imagens com detalhes que remetam a imagens naturais e fundo com conceitos que se oponham ao industrial (CLEMENTINO et al., 2017).

Ampliando a descoberta da autora supracitada sobre a cor, ela afirma que alguns aspectos se mostram relevantes para a percepção do valor ambiental em embalagens, sendo eles: 
- Paleta reduzida de cores: as embalagens que utilizaram a menor quantidade de cores em sua composição gráfica foram mais associadas à sustentabilidade pelos respondentes ( 253 no total). A associação foi decaindo de acordo com o aumento de novas cores, fator visto em dois casos experimentados. Segundo os participantes a redução na paleta de cor é associado a diminuição no uso de materiais (tinta) no processo de impressão;

- Redução no nível de saturação e claridade: os dados demonstram padrão na percepção acerca do nível de saturação e claridade empregadas na composição de embalagens alimentícias, tendo as embalagens com baixo valor de saturação e alta claridade, atingido valores altos de escolha. Na medida em que foram sendo aumentados os valores de saturação e reduzida a claridade, as embalagens passaram a perder a comunicação acerca da sustentabilidade, sendo considerável a diferença entre a escolha das embalagens com baixa saturação e as com valores mais altos. Essa associação é feita, segundo os participantes, porque cores dessaturadas aparentam requerer menor quantidade de química no seu processo de produção, o que por sua vez, traria menores danos ao meio ambiente, além disto, as cores com baixa saturação remeteriam a tintas com composição mais naturais.

Para Magnier e Schoormans (2017) no artigo How Do Packaging Material, Colour and Environmental Claim Influence Package, Brand and Product Evaluations? o sucesso de embalagens com valor ambiental depende muito da compreensão e aceitação dos consumidores. Para os autores, há necessidade de pesquisas sobre a influência dos aspectos visuais das embalagens nas avaliações acerca do valor ambiental, apresentando este campo como uma lacuna no conhecimento. Os pesquisadores realizam um experimento com 207 consumidores holandês, testando empiricamente se o material e a cor utilizados na embalagem, bem como a presença de uma reivindicação ambiental pela empresa, afetam a avaliação sobre a percepção do valor ambiental. Eles constataram que os aspectos visuais e a reivindicação ambiental influenciam as avaliações da embalagem quanto a responsabilidade da marca.

Segundo os autores, a pesquisa supracitada contribui para a literatura atual sobre sustentabilidade de embalagens, pois mostra que é possível comunicar o valor ambiental por meio de aspectos visuais estéticos. Ao analisar a influência do material e cor na avaliação da compatibilidade com o meio ambiente da embalagem, foi demonstrado especificamente que a embalagem feita de um material à base de fibra foi percebida como mais favorável ao meio ambiente do que as embalagens plásticas. Esses resultados corroboram com a literatura anterior sobre a influência do material na avaliação do valor ambiental em embalagens. Mais precisamente, confirma em um contexto experimental que os materiais à base de papel são vistos como tendo menor impacto ambiental do que os materiais plásticos. Além disso, o estudo mostra que a cor do plástico também pode influenciar a percepção do valor ambiental. A embalagem de plástico branco foi percebida como mais ecológica do que a mesma embalagem de plástico vermelho. Mais precisamente, os resultados mostram que é provável que as cores vermelhas tenham uma influência negativa na percepção de respeito pelo ambiente. Esses resultados apoiam a hipótese de que a cor desempenha um papel nas avaliações dos consumidores quanto à compatibilidade com o ambiente (IBID, 2017).

Moritz e Brockhaus (2017) no artigo Dancing in the dark: Challenges for product developers to improve and communicate product sustainability, expõem que os designers de produtos "dançam no escuro" com relação à sinalização de sustentabilidade, sendo necessário o desenvolvimento de pesquisas que supram esta lacuna. Baseado nisto, os autores apresentam as conclusões de um experimento comportamental sobre as reações dos consumidores aos esforços de sustentáveis das empresas. Na pesquisa, foram investigados como o emprego de "materiais mais sustentáveis" e "design exterior verde" influenciam as percepções dos consumidores sobre qualidade, sustentabilidade e estética dos produtos. Como resultado a análise sugere que os esforços de design exterior "verde", que aqui podemos chamar de aparência, bem como o uso de materiais mais sustentáveis, geralmente têm um efeito positivo na sustentabilidade geral percebida. No entanto, o tamanho do efeito pode variar dependendo da natureza do produto. Além disso, é revelado que ambas as estratégias podem surgir como um impedimento à qualidade percebida, assim, os designers devem examinar atentamente as preferências do cliente antes de embarcar em uma jornada para buscar um design "verde", bem como abordagens de materiais sustentáveis.

A pesquisa supracitada sugere ainda que pistas visuais através da aparência "verde" levam a reações muito mais fortes do que as descrições do material. Conclui-se assim, que a sinalização de valor ambiental é facilitada por dicas visuais, e não por escolhas de materiais que podem permanecer opacas para o cliente, apesar das informações por escrito. Deste modo, os pesquisadores alertam para que, se o objetivo for comunicar sustentabilidade, deve-se adotar pistas visuais sem perder o foco das compensações referentes à qualidade e à percepção de desempenho quando o produto tenta comunicar alto valor. 
Nas pesquisas supracitadas, é possível perceber esforços iniciais para trazer ao campo do design informações acerca dos aspectos visuais estéticos de modo a tornar as decisões dos designers mais efetivas quanto a comunicação do valor ambiental agregado. De fato, é notável o avanço nos dados trazidos a partir destas pesquisas, porém, é importante ressaltar que em todas elas os aspectos são estudados de modo isolado, ou relacionados a poucos elementos, sem que seja levado em consideração a percepção quanto ao conjunto de recursos adotados para a configuração do produto, diferente do que é proposto por vários teóricos que expressam que o processo de avaliação visual é realizado de forma global pelo individuo, em que são observadas as relações entre todos os elementos presentes, e não apenas as partes isoladas (LÖBACH, 2001; NASAR, 2000; GOMES FILHO, 2009).

$\mathrm{O}$ isolamento das informações pode trazer para o designer a percepção de que a adoção de um único recurso já se faz pertinente para a comunicação do valor ambiental, enquanto na verdade, os demais utilizados não contribuem para efetivar a mensagem. Além disto, os dados trazidos por meio das pesquisas podem não serem passíveis de adoção em todos os produtos que serão projetados, inviabilizando a melhoria na comunicação do valor ambiental. Esta constatação expõe a necessidade de soluções que possam auxiliar o designer em projetos específicos, em que os recursos passíveis de alteração possam ser levados em consideração em detrimento dos que não podem sofrer alteração, devido linguagem da marca ou qualquer outra limitação do projeto.

Pode-se afirmar ainda que, embora o designer tenha papel importante na construção de novos produtos e serviços ambientalmente corretos, o mesmo deve estar trabaIhando junto à sociedade - e a outros campos do conhecimento, levando em consideração não só a sua percepção, sobre a problemática ambiental e suas possíveis soluções, mas também incorporando as percepções dos demais envolvidos. Só deste modo o designer conseguirá avançar e transitar para busca de "Novos cenários que correspondam a estilos de vida sustentáveis' (Manzini e Vezzoli, 2016).

\section{CONSIDERAÇÕES FINAIS}

Os produtos são compostos por três funções que demandam decisões do designer durante o projeto. Entre elas, duas recebem destaque na estética atrelada ao valor ambiental de produtos que não transpareçam tal informação. A primeira é a função estética, em que o designer seleciona quais aspectos visuais serão utilizados para configurar o produto. A partir do que foi exposto, os aspectos podem ser compreendidos como estímulos ou fatores visuais que despertarão a atenção do consumidor, evocando interpretações/julgamentos mediados pelo repertório do observador, o que compõe a função simbólica. Ao estabelecer a função estética, ou seja, ao selecionar os aspectos visuais, o designer interferirá no modo como o produto será percebido, sendo isto crucial para o desenvolvimento da comunicação a partir da função simbólica, e imprescindível para o estabelecimento de uma estética sustentável para o produto.

Esta situação expõe a importância do designer para o estabelecimento e eficácia da mensagem pretendida para o produto, fortalecendo a necessidade de ferramentas que possam auxiliá-lo na tomada de decisões estéticas a partir da consulta ao público (avaliação), visto que parte destes o repertório que configurará a resposta a mensagem visual apresentada em forma de produto.

Diante da revisão realizada em variadas bases de dados de conhecimento disponíveis, foi possível destacar a pertinência de estudos focados na percepção dos indivíduos sobre os problemas provenientes do ambiente artificial que os cercam, como é o caso da comunicação do valor ambiental, sendo um anseio da sociedade voltada a mudança de paradigmas de consumo no contexto atual. É possível introduzir o repertório existente em investigações de cunho empírico. Na estética empírica encontra-se meios para compreensão das respostas subjetivas, capazes de indicar caminhos para a melhoria do processo comunicativo acerca do valor ambiental, que ocorre ao levar em consideração todos os agentes envolvidos (produtor/ emissor, a mensagem e o observador/receptor).

A partir dos estudos empíricos torna-se possível compreender como a configuração das mensagens visuais poderia comunicar o valor imbuído no produto. Sendo para isto necessário expor o consumidor a alternativas munidos dos recursos visuais recorrentes para a construção da mensagem (figura, elementos e constituição da figura) e buscar entender como estes podem ser adotados para facilitar o processo comunicativo acerca do valor ambiental. Tais informações podem gerar diretrizes mais assertivas para o projeto, bem como facilitar as decisões projetuais.

Deste modo, é possível conjecturar que as informações expressas pelo público podem contribuir para o estabelecimento de quais e como os aspectos visuais estéticos poderiam diferenciar os produtos ecologicamente orientados dos demais, a partir da avaliação do público. Este caminho pode viabilizar a redução dos ruídos presentes em produtos que, mesmo contendo valor ambiental, aparentemente tem similaridade com os produtos 
convencionais. Os designers podem, a partir dos dados gerados, criar uma aparência coerente ao produto, relacionando as funções prática e estética à função simbólica dos produtos com valor ambiental agregado.

Para avaliar a Qualidade Visual atrelada ao valor ambiental, parte-se do princípio de que os aspectos visuais estéticos podem ser configurados de modo a comunicar informações acerca da orientação do produto, podendo uma mensagem ser mais eficaz que outra a partir da configuração. Assim, entende-se que, existem formas de organizar os aspectos visuais estéticos de modo a desenvolver uma mensagem mais clara, sendo este um problema de design.

Para estudar como os aspectos visuais podem contribuir para o estabelecimento de uma estética sustentável, ficou evidente a relevância da correlação entre eles, visto que os indivíduos não observam isoladamente cada recurso visual utilizado, mas aprecia a completude. É pertinente que haja ferramentas capazes de auxiliar o designer a selecionar os recursos visuais mais adequados, favorecendo a comunicação do valor ambiental, considerando os demais, inclusive os que não corroboram com a mensagem estabelecida (limitações).

\section{CONCLUSÕES}

É possível perceber esforços iniciais para trazer ao campo do design informações acerca dos aspectos visuais estéticos de modo a tornar as decisões dos designers mais efetivas quanto a comunicação do valor ambiental agregado. Pode-se afirmar que embora o designer tenha papel importante na construção de novos produtos e serviços ambientalmente corretos, deve também estar trabalhando junto à sociedade para buscar alternativas que contribuam para melhorar a comunicação entre os produtos ecologicamente orientados e os consumidores.

É preciso considerar não só a problemática ambiental e suas possíveis soluções, mas também incorporar as percepções dos demais envolvidos para o processo de diferenciação dos produtos com valor ambiental, sendo um caminho pertinente, pesquisas de cunho estético mediante métodos pautados na estética empírica.

\section{REFERÊNCIAS}

BENSE, Max. Pequena estética. 3 ed. São Paulo: Perspectiva, 2009. ISBN: 978-85-273-0385-9.

BOMFIM, Gustavo Amarante. Notas de Aula sobre Design e Estética. Rio de Janeiro: PUC-RIO, Departamento de Artes \& Design - Laboratório da Representação Sensível, 2001.

BONSIEPE, Gui. Design, Cultura e Sociedade. São
Paulo: Blucher, 2011.

BÜRDEK, Bernard E. História, teoria e prática do design de produtos. São Paulo: Edgard, 2006. ISBN 85-212-0375-6

CARDOSO, Rafael. Design para um mundo complexo. São Paulo: COSAC NAIFY, 2013. 264 p. ISBN 978-85-405-0098-3.

CASTRO, Maria Luiza A. C. Da ética construtivista à ética sustentável: a trajetória do design. Cadernos de pós-graduação em arquitetura e urbanismo. v. $8, \mathrm{n}$. 1, 2008.

CLEMENTINO, Thamyres Oliveira; SILVA. Itamar Ferreira; FERNANDES, Tâmila Kassimura. Avaliação da percepção dos consumidores sobre a dimensão ecológica das embalagens alimentícias: uma análise visual. REVISTA EDUCAÇÃO GRÁFICA, v. 21, p. 1-23, 2017.

CLEMENTINO, T.O.; ARRUDA, A. J. V. . A influência dos requisitos projetuais sustentáveis na estética das embalagens ecologicamente orientadas. ESTUDOS EM DESIGN (ONLINE), v. 26, p. 2, 2018.

FARINA, Modesto. Psicodinâmica das cores em comunicação. São Paulo: Edgard Blucher. 2011.

GOMES FILHO, João. Gestalt do Objeto: síntese de Leitura Visual da Forma. 9 ed. São Paulo: Escrituras Editora, 2009. 133 p. ISBN 978-85-86303-57-9.

INSTITUTO AKATU. Pesquisa Akatu 2018: panorama do consumo consciente no brasil: desafios, barreiras e motivações. Disponível em:< https://www.akatu.org.br/arquivos/Pesquisa_akatu_apresentacao.pdf. Acesso em: 10 de janeiro de 2019.

KAZAZIAN, Thierry. Haverá a idade das coisas leves: design e desenvolvimento sustentável. 2 ed. São Paulo: Editora Senac são Paulo, 2009. 193 p. ISBN 978-85-7359-803-2.

KRUKEN, Lia; TRUSEN, Christoph. A comunicação da sustentabilidade em produtos e serviços. In: MORAES, D.; (org.). Cadernos de estudos avançados em Design: sustentabilidade I. Barbacena, MG: Editora da Universidade do Estado de Minas Gerais EdUEMG, 2009. p. 59-68. ISBN 978-85-62578-00-7.

LÖBACH, B. Design Industrial: bases para a configuração de produtos industriais. São Paulo: Edgard Blücher, 2001. 208 p. ISBN 85-212-0288-1.

LUCHS,Michael G; kumar, Minu. "Yes, but this Other One Looks Better/Works Better": How do Consumers Respond to Trade-offs Between Sustainability and Other Valued Attributes? J Bus Ethics (2017) 140: 567584. DOI 10.1007/s10551-015-2695-0.

MAGNIER, Lise; SCHOORMANS, Jan. How Do Packaging 
Material, Colour and Environmental Claim Influence Package, Brand and Product Evaluations? Packaging. Technology and Science, 2017. 30(11), 735-751. doi:10.1002/pts.2318

MANZINI, Ezio; VEZZOLI, Carlo. O desenvolvimento de Produtos Sustentáveis: os requisitos ambientais dos produtos industriais. 1 ed. São Paulo: Editora da Universidade de São Paulo, 2016. 366 p. ISBN 978-85-314-0731-4.

MORITZ, Petersen; BROCKHAUS, Sebastian. (2017). Dancing in the dark: Challenges for product developers to improve and communicate product sustainability. Journal of Cleaner Production, 161, 345-354. doi:10.1016/j.jclepro.2017.05.127

NASAR, J. The evaluative image of places. In W. Bruce Walsh; Kenneth H Craik; Richard H. Price. 2000. 2nd ed. (Eds). Person-environment psychology: new directions and perspectives, pp 117-168. New Jersey: Lawrence Erlbaum Associates, 2000.

ORSATO, Renato J. Posicionamento ambiental estratégico. Identificando quando vale a pena investir no verde. REAd - Revista Eletrônica de Administração. UFRGS, v. 8, n. 6, p. 1-29, nov. 2002

ORSATO, Renato J. Competitive Environmental Strategies: WHEN DOES IT PAY TO BE GREEN? California management review. University of California, Berkeley, v. 48, n.2, p.127-142. 2006.

PANTALEÃO, Lucas Farinelli; PINHEIRO, Olympio José; MENEZES, M. S. Teoria e prática, ética e estética no design de produtos: questões de sustentabilidade como alternativa para subversão da atual cultura material de consumo. CIMODE 2016 - 3 ० Congresso Internacional de Moda e Design, 2016.

SALEK, Felipe Lopes de Lima; FORMIGA, Eliana. Green wash my hair: um estudo acerca das percepções de sustentabilidade em embalagens de xampu e condicionador sob a ótica do consumidor. In: SEMIC Seminário de iniciação científica, 2015. São Paulo. Anais... São Paulo: ESPM. ISSN 2358-2138.

SANTOS, Ivan Mota. Avaliação da percepção dos usuários sobre a comunicação da sustentabilidade em produtos: o modelo Persus. 2012. 104 f. Dissertação (Mestrado em Design) - Universidade do Estado de Minas Gerais, Belo Horizonte 2012.

SILVEIRA, N. B. da M. Morfologia do objeto: uma abordagem da gramática visual/formal aplicada ao design de artefatos materiais tridimensionais. Tese (Doutorado em Design) - Universidade Federal de Pernambuco, Recife, 2018. $181 \mathrm{f}$.
WALKER, Stuart. Desmascarando o objeto: reestruturando o design para sustentabilidade. Revista Design em Foco, Bahia, vol.2, n.2, p. 47-62. 2005.

VEZZOLI, Carlo. Design de sistemas para a sustentabilidade. 1 ed. Salvador: EDUFBA, 2010. 342 p. ISBN 978-85-232-0722-9

ZAFARMAND, Seyed Javad; SUGIYAMA, Kazuo; WATANABE, Makoto. Aesthetic and Sustainability: The Aesthetic Attributes Promoting Product Sustainability. The Journal of Sustainable Product Design, 2003. 3(3-4), p. 173-186. doi:10.1007/s10970-005-6157-0

\section{AGRADECIMENTOS}

Agradecemos a CAPES pelo fomento a esta pesquisa; ao PPGDesign da UFPE e PPGDesign da UFCG, pelo suporte fornecido através dos professores orientadores deste trabalho; e ao grupo de pesquisa BIODESIGN ao qual fazemos parte. 


\section{AUTORES}

ORCID: https://orcid.org/0000-0003-1323-2831

THAMYRES OLIVEIRA CLEMENTINO, M.Sc. | Professora de Design na Unidade Acadêmica de Design - UFCG, Campina Grande, Paraíba (PB) - Brasil | Correspondência para: R. Tv. Américo Carneiro, 301 - Jardim 40, Campina Grande - PB, 58416-053 | e-mail: thamyres.oliveira.clementino@gmail. com | Lattes: http://lattes.cnpq.br/7207288359171040

ORCID: https://orcid.org/0000-0003-4551-4497

AMILTON JOSÉ VIEIRA DE ARRUDA, PhD. | Universidade Federal de Pernambuco | Programa de Pós-graduação em Design | Recife, PERNAMBUCO (PE) - Brasil| Correspondência para: R. General Adauto Gomes Barbosa, 94 Apt 302 - Várzea, Recife - PE, 50741-280 |E-maill:arruda.amilton@gmail.com

ORCID: https://orcid.org/0000-0002-0874-9345

ITAMAR FERREIRA DA SILVA, Dr. | Coordenador do PPGDesign UFCG | Professor na Unidade Acadêmica de Design - UFCG, Campina Grande, Paraíba (PB) - Brasil | Correspondência para: Universidade Federal de Campina Grande, Unidade acadêmica de Design, 58429900 - Campina Grande, PB Brasil | e-mail: itamarfs0210@gmail.com | Lattes: http:// lattes.cnpq.br/7437181641061519

\section{COMO CITAR ESTE ARTIGO}

CLEMENTINO, Thamyres Oliveira; ARRUDA, Amilton José Vieira de; SILVA, Itamar Ferreira da. Estética da Sustentabilidade: $O$ Valor Ambiental Percebido Por Meio dos Aspectos Visuais do Produto. MIX Sustentável, [S.I.], v. 6, n. 2, p. 123-138, mai. 2020. ISSN 24473073. Disponível em:<http://www.nexos. ufsc.br/index.php/mixsustentavel>. Acesso em: dia mês. ano. doi:https://doi.org/10.29183/2447-3073. MIX2020.v6.n2.123-138. 
